\title{
Two unexpected promiscuous activities of the iron-sulfur protein IspH in production of isoprene and isoamylene
}

\author{
Deyong Ge ${ }^{1,2,3}$, Yanfen Xue ${ }^{1}$ and Yanhe Ma ${ }^{1 *}$
}

\begin{abstract}
Background: Bacillus species, possessing the methylerythritol phosphate (MEP) pathway for the synthesis of isoprenoid feedstock, are the highest producers of isoprene among bacteria; however, the enzyme responsible for isoprene synthesis has not been identified. The iron-sulfur protein IspH is the final enzyme of the MEP pathway and catalyses the reductive dehydration of (E)-4-hydroxy-3-methyl-2-butenyl diphosphate (HMBPP) to form isopentenyl diphosphate and dimethylallyl diphosphate (DMAPP). In this study, we demonstrated two unexpected promiscuous activities of IspH from alkaliphilic Bacillus sp. N16-5, which can produce high levels of isoprene.

Results: Bacillus sp. N16-5 IspH could catalyse the formation of isoprene from HMBPP and the conversion of DMAPP into a mixture of 2-methyl-2-butene and 3-methyl-1-butene. Both reactions require an electron transfer system, such as that used for HMBPP dehydration. Isoprene and isoamylene synthesis in Bacillus sp. N16-5 was investigated and the reaction system was reconstituted in vitro, including $\mathrm{IspH}$, ferredoxin and ferredoxin-NADP+${ }^{+}$-reductase proteins and NADPH. The roles of specific IspH protein residues were also investigated by site-directed mutagenesis experiments; two variants (H131N and E133Q) were found to have lost the HMBPP reductase activity but could still catalyse the formation of isoprene. Overexpression of IspH H131N in Bacillus sp. N16-5 resulted in a twofold enhancement of isoprene production, and the yield of isoprene from the strain expressing E133Q was increased $300 \%$ compared with the wild-type strain.
\end{abstract}

Conclusions: IspH from Bacillus sp. N16-5 is a promiscuous enzyme that can catalyse formation of isoprene and isoamylene. This enzyme, especially the $\mathrm{H} 131 \mathrm{~N}$ and $\mathrm{E} 133 \mathrm{Q}$ variants, could be used for the production of isoprene from HMBPP.

Keywords: Bacillus, Isoprene, 2-Methyl-2-butene, 3-Methyl-1-butene, (E)-4-Hydroxy-3-methyl-2-butenyl diphosphate (HMBPP), Dimethylallyl diphosphate (DMAPP), Isoprene synthase, IspS, IspH

\section{Background}

Isoprene and isoamylene are important platform chemicals in the synthetic chemistry industry. There are very few organisms which can produce isoamylene, while isoprene is one of the most abundant natural products in the environment and can be produced naturally by a wide variety of organisms, including animals, plants, and bacteria [1-3]. Isoprene production in plants has been

\footnotetext{
*Correspondence: mayanhe@im.ac.cn

${ }^{1}$ State Key Laboratory of Microbial Resources, Institute of Microbiology, Chinese Academy of Sciences, Beijing 100101, People's Republic of China Full list of author information is available at the end of the article
}

well studied, and isoprene synthase (IspS) has been identified from several plants, such as kudzu and poplar [4, 5]. The enzyme catalyses the conversion of dimethylallyl diphosphate (DMAPP) to isoprene by elimination of pyrophosphate in a divalent cation-dependent reaction [6]. Bacillus species are found to be the highest producers of isoprene among bacteria [3], however, the enzyme responsible for isoprene synthesis has not been identified. Previous reports revealed that Bacillus subtilis contained an isoprene synthase activity that catalyses DMAPP-dependent isoprene formation, but the activity was very labile [7]. 
There are two natural pathways for biosynthesis of DMAPP which is the precursor of isoprene: the mevalonic acid (MVA) pathway and the methylerythritol 4-phosphate (MEP) pathway [8-11]. The last enzyme in the MEP pathway is 4-hydroxy-3-methyl-butenyl diphosphate reductase $(\mathrm{IspH})$, which contains a [4Fe-4S] cluster with a unique fourth iron not coordinated to any amino acid residue and which catalyses the reductive dehydration of (E)-4-hydroxy-3-methyl-2-butenyl diphosphate (HMBPP) to form an approximate 5:1 mixture of isopentenyl diphosphate (IPP) and DMAPP [1216]. This conversion is a reductive process that requires a special electron transport system to provide two electrons to the substrate. In Escherichia coli, a system consisting of NADPH, flavodoxin, and flavodoxin reductase has been proposed to be the natural electron source for IspH $[14,15,17]$. Many studies in vitro have also demonstrated that $E$. coli IspH catalytic activity is detected in the presence of this system. IspH from the malaria parasite Plasmodium falciparum, which has no flavodoxin protein, uses ferredoxin $(\mathrm{Fd})$ and ferredoxin-NADP ${ }^{+}$ reductase (FNR) as the reduction system [18].

Some substrate analogues are also converted by the IspH protein $[19,20]$. In addition, IspH has been found to show acetylene hydratase activity, and catalyse the hydration of acetylenes to aldehydes and ketones [21]. These observations indicate that IspH is promiscuous in its catalytic activity. In this work, we revealed two further unexpected promiscuous reactions of IspH (Fig. 1), the formation of isoprene from HMBPP, and the conversion of DMAPP into a mixture of 2-methyl-2-butene (2M2B) and 3-methyl-1-butene (3M1B).

\section{Results}

Overexpression of ispH resulted in isoprene and isoamylene synthesis

We found that alkaliphilic Bacillus sp. N16-5 could produce a high level of isoprene; the maximum production reached $75 \mu \mathrm{g} \mathrm{L}^{-1} \mathrm{OD}^{-1}\left(1 \mathrm{OD}_{600}\right.$ of $1 \mathrm{~L}$ bacterial culture produce $75 \mu \mathrm{g}$ of isoprene). To identify the gene responsible for isoprene biosynthesis in the strain, a fosmid library was constructed and screened. The isoprene synthase gene was not found. However, a clone strain produced two unknown substances and a small amount of isoprene compared with other clones, as determined by gas chromatography (GC) analysis of the headspace of liquid cultures (Additional file 1: Figure S1). These two unknown substances were identified as $2 \mathrm{M} 2 \mathrm{~B}$ and 3M1B by GC-MS analysis (Additional file 1: Figure S2). After investigation of genes in DNA fragments that were ligated into the fosmid vector harboured by this clone, we concluded that the ispH gene encoding the IspH protein and the fer gene encoding a [4Fe-4S] type ferredoxin were involved in isoamylene synthesis.

Plasmid pSTV165H, encoding the Bacillus sp. N16-5 ispH gene, and plasmid pSTV165HF, encoding the ispH and fer genes, were constructed and transformed into the E. coli strain Trans109. E. coli Trans109 containing pSTV165HF could produce 2M2B and 3M1B, whereas the strain containing pSTV165H produced little isoamylene. This indicated that IspH was able to produce isoamylene in vivo in the presence of ferredoxin, which generally functions as an electron mediator in a variety of metabolic processes. To test whether the IspH proteins from E. coli and B. subtilis synthesised isoamylene,

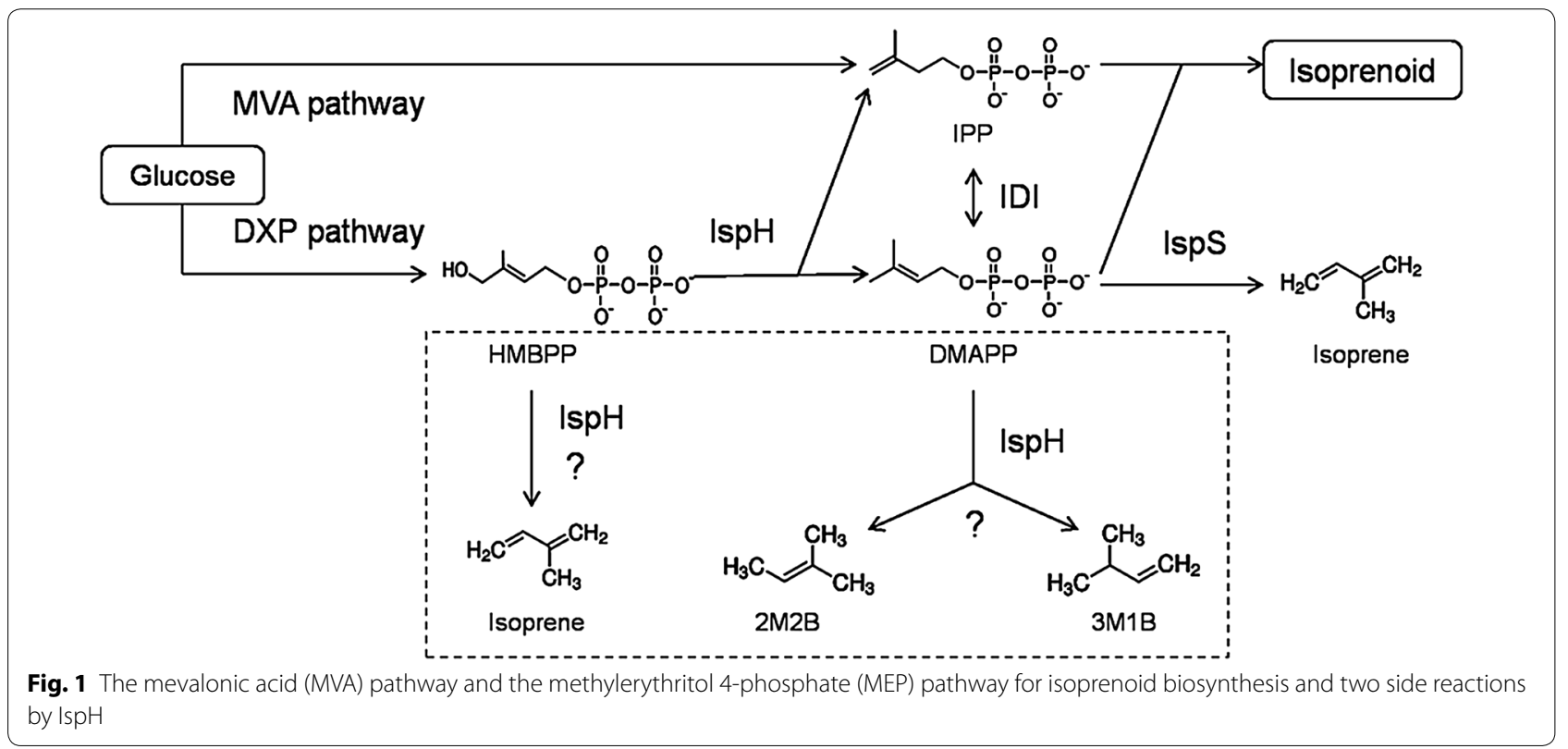


plasmids pSTV12HF (encoding E. coli $\mathrm{K} 12$ ispH and $f l d$ ) and pSTV168HF (encoding B. subtilis ispH and fer) were constructed and respectively transformed into E. coli Trans109. Both recombinant strains could produce isoamylene. The maximum production by $E$. coli containing pSTV12HF was $3.8 \mu \mathrm{g} \mathrm{L}^{-1} \mathrm{OD}^{-1}$, compared with $7.6 \mu \mathrm{g} \mathrm{L}^{-1} \mathrm{OD}^{-1}$ for $E$. coli containing pSTV168HF, and $9.2 \mu \mathrm{g} \mathrm{L}^{-1} \mathrm{OD}^{-1}$ for E. coli containing PSTV165HF. These results indicated that the activity of IspH from different species might be different.

Although E. coli containing pSTV165HF could produce 2M2B and 3M1B, Bacillus sp. N16-5 emitted little isoamylene. This may be because of the low concentration of IspH since there is only one copy of the $i s p H$ gene on the chromosome. To enhance IspH expression, plasmid $\mathrm{pMH}$ was constructed, harbouring the $i s p H$ gene under the control of the promoter of the Bacillus sp. N16-5 lactate dehydrogenase gene $l d h$, and transformed into Bacillus sp. N16-5. As expected, strain N16-5 containing the pMH plasmid produced up to $57.5 \mu \mathrm{g} \mathrm{L} \mathrm{L}^{-1} \mathrm{OD}^{-1}$ of $2 \mathrm{M} 2 \mathrm{~B}$ and $11.6 \mu \mathrm{g} \mathrm{L}^{-1} \mathrm{OD}^{-1}$ of $3 \mathrm{M} 1 \mathrm{~B}$, much more than the wild-type strain (Fig. 2). However, the isoprene production of strain N16-5 remained the same. Notably, the ratio of $2 \mathrm{M} 2 \mathrm{~B}$ and $3 \mathrm{M} 1 \mathrm{~B}$ was approximately $5: 1$. Interestingly, the ratio was similar to that of IPP and DMAPP produced by IspH.

\section{Expression and purification of recombinant proteins}

The aforementioned results implied that an unknown substance might be converted into isoamylene in a reaction catalysed by IspH in presence of ferredoxin. To test this possibility, IspH protein, ferredoxin and ferredoxin$\mathrm{NADP}^{+}$-reductase were each expressed with a C-terminal His-tag. These recombinant proteins were directly used for an enzyme activity assay. Notably, IspH contains

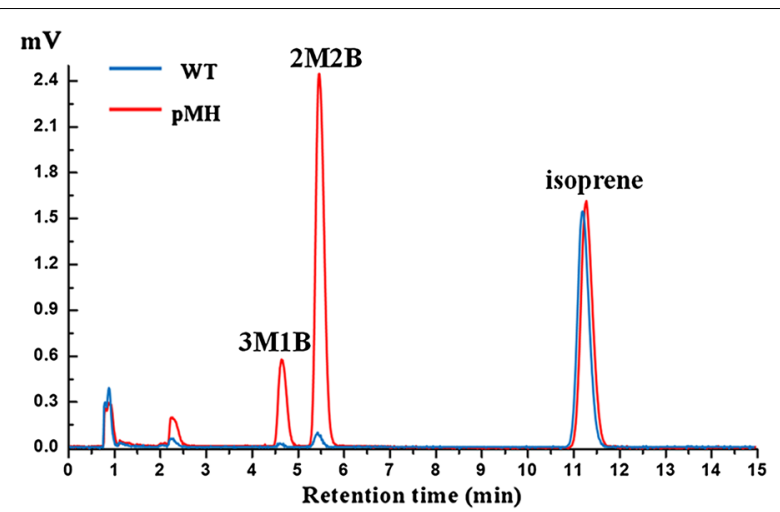

Fig. 2 GC profile of headspace of Bacillus sp. N16-5 (wild-type) and engineered strain $\mathrm{N} 16-5$ containing the $\mathrm{pMH}$ plasmid with ispH gene after incubation at $37^{\circ} \mathrm{C}$ for $12 \mathrm{~h}$. The retention times of $3 \mathrm{M} 1 \mathrm{~B}, 2 \mathrm{M} 2 \mathrm{~B}$ and isoprene are 4.5, 5.5 and $11.3 \mathrm{~min}$, respectively an iron-sulfur cluster, which may be crucial for catalytic activity and must be assembled by special biochemical machinery. Therefore, to improve the production of fully functional IspH, we used an iron-sulfur cluster biosynthesis hyperexpression strain, which has been described previously [15]. The purified recombinant IspH protein was intensely brown and appeared homogeneous after elution judged by sodium dodecyl sulphate (SDS) polyacrylamide gel electrophoresis (Fig. 3a). The absorption spectrum of the recombinant IspH had typical characteristics of iron-sulfur proteins with a maximum at approximately $410 \mathrm{~nm}$, a shoulder at approximately $320 \mathrm{~nm}$, and a peak at approximately $280 \mathrm{~nm}$. The ratio of $E_{410} / E_{280}$ was 0.3 (Fig. 3b).

\section{Isoprene and isoamylene production by IspH in vitro}

To assess whether purified recombinant IspH protein catalyses the formation of isoamylene from its substrate, IspH was incubated with NADPH, Fd, and FNR, which might be the in vivo IspH reducing system, and each of three potential substrates, HMBPP, IPP and DMAPP, in 5 - $\mathrm{mL}$ sealed chromatography vials in anaerobic conditions (Table 1). The assay mixture without recombinant IspH was used as a negative control. The vial headspace was detected by GC-MS to identify isoamylene and isoprene. DMAPP could be converted to $2 \mathrm{M} 2 \mathrm{~B}$ and $3 \mathrm{M} 1 \mathrm{~B}$ by IspH in the presence of the NADPH-Fd-FNR reductant system (Table 1). There was a small amount of isoprene in the headspace of the vial containing DMAPP, which did not increase significantly compared with the negative control. The product ratio of $2 \mathrm{M} 2 \mathrm{~B}$ to $3 \mathrm{M} 1 \mathrm{~B}$ was approximately 8.5:1, which was different from the $5: 1$ ratio observed in vivo. When HMBPP was used as substrate of the recombinant $\mathrm{IspH}$, isoprene was, surprisingly, produced in the vial headspace, while no isoprene was detected in the negative control. As the reaction proceeded, $2 \mathrm{M} 2 \mathrm{~B}$ and $3 \mathrm{M} 1 \mathrm{~B}$ were also detected in the headspace. We suggest that the DMAPP originating from HMBPP was further converted to isoamylene, but the isoprene in the vial headspace was directly derived from HMBPP by IspH. IPP was not converted to isoamylene or isoprene by IspH in our conditions.

A series of tests were performed in anaerobic conditions to confirm that each component of the reaction system was essential for the conversion of DMAPP/HMBPP (Additional file 1: Table S1). The results demonstrated that the recombinant IspH protein that catalysed the formation of isoamylene and isoprene required ferredoxin and FNR proteins in addition to NADPH as a cofactor. Bacillus sp. N16-5 has a flavodoxin that might be another mobile electron carrier; however, when it was substituted for Fd in the test, DMAPP and HMBPP could not be converted to isoamylene and isoprene by IspH. The addition 


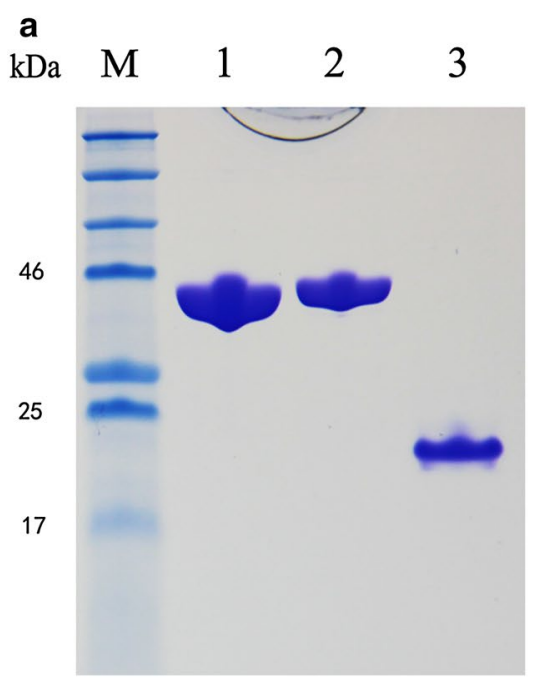

b

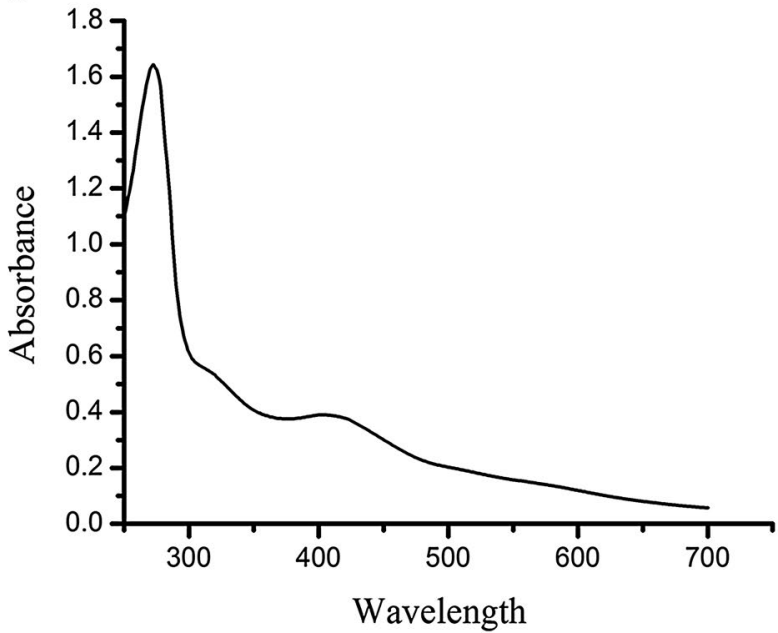

Fig. 3 SDS polyacrylamide gel electrophoresis and UV-Vis spectrum of recombinant IspH protein. a SDS-PAGE: Lane M, molecular weight markers; lane 1, FNR protein; lane 2, IspH; lane 3, ferredoxin. b UV-Vis spectrum of recombinant IspH (1.5 mg mL ${ }^{-1}$ ) recorded in $20 \mathrm{mM}$ Tris- $\mathrm{HCl}$, $\mathrm{pH} 7.8$. The spectrum shows a maximum at $410 \mathrm{~nm}$ and a shoulder at 320, indicating the presence of an iron-sulphur cluster

Table 1 Enzyme tests with IspH

\begin{tabular}{lllll}
\hline Substrate & \multicolumn{3}{l}{ Products in the headspace $(\mathbf{n g} / \mathbf{m L})$} & [2M2B]:[3M1B] \\
\cline { 2 - 4 } & Isoprene & 2M2B & 3M1B & \\
\hline DMAPP & $+^{\text {a }}$ & $39.1 \pm 3.9$ & $4.58 \pm 0.6$ & $8.5: 1$ \\
IPP & - & - & - & \\
HMBPP & $21.6 \pm 2.3$ & $6.23 \pm 1.1$ & $0.83 \pm 0.1$ & $7.5: 1$
\end{tabular}

Values are presented as the average \pm standard deviation of three independent experiments

The reaction was performed in $20 \mathrm{mM}$ Tris- $\mathrm{HCl}$ buffer $(\mathrm{pH} 7.8)$ containing $150 \mathrm{mM} \mathrm{NaCl}$ at $37^{\circ} \mathrm{C}$ for $1 \mathrm{~h}$

a Trace amount of isoprene, as was also observed in the negative control

of $\mathrm{Mg}^{2+}$ was not required for IspH activity in isoamylene and isoprene synthesis. To determine the kinetic parameters, IspH activity toward DMAPP was measured with DMAPP concentrations from 0.1 to $1 \mathrm{mM}$ (Additional file 1: Figure S3). Based on Michaelis-Menten and Lineweaver-Burk plots, the DMAPP $K_{\mathrm{M}}$ was calculated to be approximately $275 \mu \mathrm{M}$. The maximal catalytic activ-

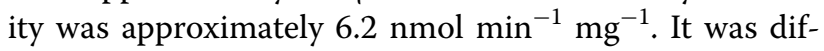
ficult to determine the activity of IspH with HMBPP for isoprene formation because HMBPP was mostly transformed into IPP and DMAPP, and the latter could be further converted to isoamylene by IspH. In our test, the maximal activity obtained for the formation of isoprene

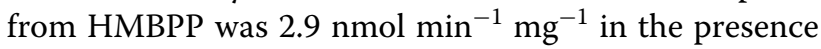
of the NADPH-Fd-FNR reductant system. The recombinant IspH could also use reduced methyl viologen as an artificial electron donor, and the activity of IspH for isoprene formation was $3.5 \mathrm{nmol} \mathrm{min} \mathrm{mg}^{-1}$, slightly higher than that of IspH using its putative natural reducing system.

\section{Enzymatic activity assays in $\mathrm{D}_{2} \mathrm{O}$}

To investigate proton transfer in these two reactions catalysed by IspH, enzymatic activity assays were performed in $80 \%(\mathrm{v} / \mathrm{v}) \mathrm{D}_{2} \mathrm{O}$ buffer and the products were identified by GC-MS. Protons are likely to derive from the bulk water of the reaction system; if the reaction is performed in $\mathrm{D}_{2} \mathrm{O}$ buffer, the molecular weight of the products of IspH would be increased, and the major peaks in the mass spectra would differ from those in $\mathrm{H}_{2} \mathrm{O}$ buffer. As expected, the mass spectrum showed that the ratios of fragment ions $71 / 70$ and $56 / 55$ of $2 \mathrm{M} 2 \mathrm{~B}$ produced by IspH in $\mathrm{D}_{2} \mathrm{O}$ buffer were significantly enhanced compared with the results in $\mathrm{H}_{2} \mathrm{O}$ buffer (Fig. 4); this fact suggested that the pyrophosphate group of DMAPP was eliminated and a proton from the bulk water could be used to form deuterium-2M2B. However, the abundance of fragment ion 70 was still greater than that of 71 in the mass spectrum, which was not consistent with the prediction based on the $\mathrm{H}_{2} \mathrm{O} / \mathrm{D}_{2} \mathrm{O}$ ratio (1:4). In contrast to isoamylene, the mass spectrum of isoprene produced by IspH in $\mathrm{D}_{2} \mathrm{O}$ buffer remained unchanged, which demonstrated that $\mathrm{C} 4$ and $\mathrm{C} 1$ of HMBPP did not accept a proton after loss of the hydroxyl and pyrophosphate groups.

\section{Role of ferredoxin and flavodoxin in isoamylene and isoprene synthesis in vivo}

Bacillus sp. N16-5 has one [4Fe-4S] type ferredoxin and one flavodoxin. To evaluate whether they are required 


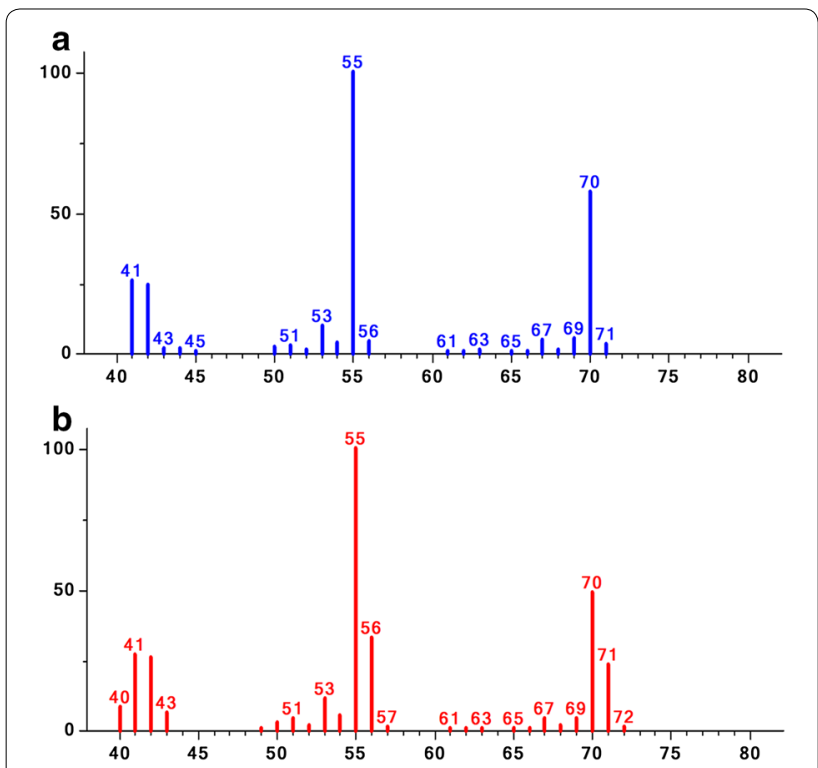

Fig. 4 Mass spectrum of isoamylene. a Mass spectrum of $2 M 2 B$ produced by the reaction that was performed in $\mathrm{H}_{2} \mathrm{O}$ buffer. b Mass spectrum of $2 \mathrm{M} 2 \mathrm{~B}$ produced by the reaction that was performed in $80 \%(\mathrm{v} / \mathrm{v}) \mathrm{D}_{2} \mathrm{O}$ buffer for isoamylene and isoprene synthesis in vivo, we constructed strain N165D1, which is a fer (ferredoxin) gene knockout, and strain N165D2, which is a fld (flavodoxin) gene knockout. Both mutant strains grew almost normally in Horikoshi-I medium (Fig. 5a). This result suggests that ferredoxin and flavodoxin are not essential for IspH activity in Bacillus sp. N16-5, which utilises the MEP isoprenoid biosynthesis pathway to produce IPP and DMAPP, two universal precursors of terpenes. However, the production of isoprene emitted by strain N165D1 was reduced by approximately $50 \%$ compared with the wild-type strain. In contrast, isoprene production by strain N165D2 was close to that of the wild-type strain (Fig. 5b). Because IspH overexpression in Bacillus sp. N16-5 resulted in much more isoamylene production (see above), plasmid pMH, containing the ispH gene, was transformed into the mutant strains $\mathrm{N} 165 \mathrm{D} 1$ and N165D2. Strain N165D1 harbouring pMH produced little isoamylene, while strain N165D2 harbouring pMH produced $32 \mu \mathrm{g} \mathrm{L}^{-1} \mathrm{OD}^{-1}$ isoamylene, which was approximately half the level of the wild-type strain harbouring pMH (Fig. 5c). These results indicated that the absence
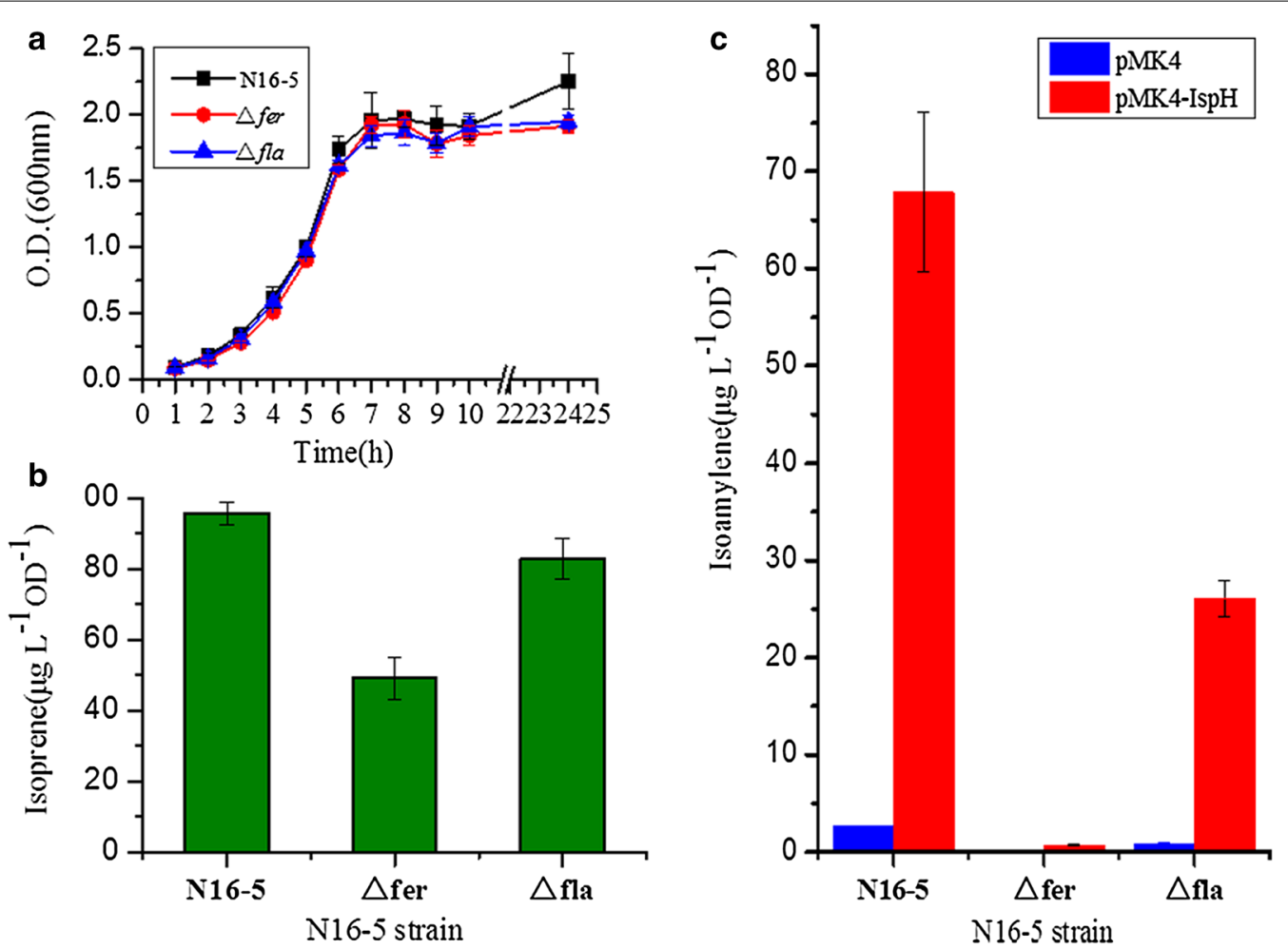

Fig. 5 Growth phenotype and isoprene and isoamylene production by Bacillus sp. N16-5 and its derivatives. a Bacillus sp. N16-5 (wild-type), N165D1 $(\Delta f e r)$ and N165D2 $(\Delta f l d)$ strains were grown in Horikoshi-I medium at $37^{\circ} \mathrm{C}$ on a rotary shaker at $220 \mathrm{rpm}$. $\mathbf{b}$ Isoprene production by these strains. c Isoamylene production by these strains when containing pMK4 or pMH plasmid with ispH gene. Error bars represent the standard deviations of three replicates 
of ferredoxin not only reduced isoprene production by half but nearly blocked isoamylene synthesis in Bacillus sp. N16-5. Combined with our in vitro enzymatic activity assay results, these findings demonstrate that ferredoxin is more efficient than flavodoxin as an electron donor to IspH in Bacillus sp. N16-5.

\section{The roles of IspH protein residues in the promiscuous activities}

Based on previous reports, there are several highly conserved amino acid residues that contribute to IspH activity toward HMBPP [22-25]. To investigate the roles of these conserved amino acids in the promiscuous activities of $\mathrm{IspH}$, the corresponding IspH variants were constructed. As described above, E. coli Trans109 harbouring plasmid pSTV165HF, used for coexpression of the Bacillus sp. N16-5 ispH and fer genes, could produce isoamylene and isoprene; therefore, IspH variants activity could be determined by quantitative analysis of isoamylene and isoprene produced by recombinant strains containing protein variants. Replacement of the strictly conserved His131 ( $\mathrm{H} 124$ in E. coli $\mathrm{IspH}$ ) by Asn, or Glu133 (E126 in E. coli IspH) by Gln, led to loss of isoamylene synthesis activity (Additional file 1: Figure S4), but both IspH variants could still produce isoprene.

For confirmation of these results, in vitro enzymatic activity assays were performed in anaerobic conditions. The $\mathrm{H} 131 \mathrm{~N}$ and E133Q IspH variant proteins were expressed and purified. The purified recombinant IspH variants were incubated with DMAPP or HMBPP in the presence of the NADPH-Fd-FNR reductant system in 5-mL sealed chromatography vials. DMAPP was not converted to isoamylene by either the H131N or E133Q IspH variant proteins, however, both could catalyse the formation of isoprene from HMBPP; the maximal activities of the $\mathrm{H} 131 \mathrm{~N}$ and E133Q IspH variant proteins were 2.5 and $3.1 \mathrm{nmol} \mathrm{min}^{-1} \mathrm{mg}^{-1}$, respectively. It was notable that IspH H131 and E133 are strictly conserved and play a crucial role in the activity toward HMBPP $[23,24,26]$. To examine whether the H131N and E133Q IspH variant proteins could catalyse the transformation of HMBPP into DMAPP and IPP, their reaction products were analysed by an acid hydrolysis method, as described in previous reports $[27,28]$. The two variant proteins lost the HMBPP reductase activity, which was consistent with previous reports $[23,25]$. As a consequence, the $\mathrm{H} 131 \mathrm{~N}$ or E133Q IspH variants could be seen as isoprene synthases specialized for the conversion of HMBPP into isoprene.

To further investigate the activities of the H131N and E133Q IspH variants in Bacillus sp. N16-5, the corresponding $\mathrm{pMH}$ variants were obtained by site-directed mutagenesis and transformed into Bacillus sp. N16-5 to construct strains BSH131N and BSE133Q, respectively. After analysis of the headspace of cultures of these bacteria by $\mathrm{GC}-\mathrm{MS}$, we found that isoprene production by strain BSH131N was increased to three times the level of that by the wild-type strain, i.e. up to $235 \mu \mathrm{g} \mathrm{L}^{-1} \mathrm{OD}^{-1}$; isoprene emitted by the BSE133Q strain reached approximately $352 \mu \mathrm{g} \mathrm{L}^{-1} \mathrm{OD}^{-1}$ (Fig. 6). Neither strain emitted isoamylene. These results suggest that the $\mathrm{H} 131 \mathrm{~N}$ and E133Q IspH variant proteins can be used for isoprene production.

\section{Discussion}

Over the years, IspH, the last enzyme in the MEP pathway, has received considerable attention because it is not present in humans but is essential for microorganisms and thus is a viable target for the development of new antimicrobial drugs [29-31]. The structure and reaction mechanisms of IspH have been extensively studied. Based on previous reports, IspH shows promiscuous activity toward acetylenes. It can convert but-3-ynyl diphosphate and pent-4-ynyl diphosphate into an aldehyde and a ketone respectively [21]. In the present work, we have determined that IspH catalyses two unexpected side reactions in addition to its main catalytic activity. One is the elimination of DMAPP pyrophosphate to form $2 \mathrm{M} 2 \mathrm{~B}$ and $3 \mathrm{M} 1 \mathrm{~B}$. The ratio of the two isoamylenes produced by Bacillus sp. N16-5 IspH in vivo was approximately 5:1, while in in vitro enzymatic activity assays, the ratio was approximately 8.5:1. Interestingly, E. coli IspH also produced isoamylenes, but the in vivo assay demonstrated a 2M2B:3M1B ratio of approximately 1.5:1 (Additional file 1: Figure S5). The other side reaction is the formation of isoprene from HMBPP, which is used as substrate to produce IPP and DMAPP by IspH in the MEP pathway.

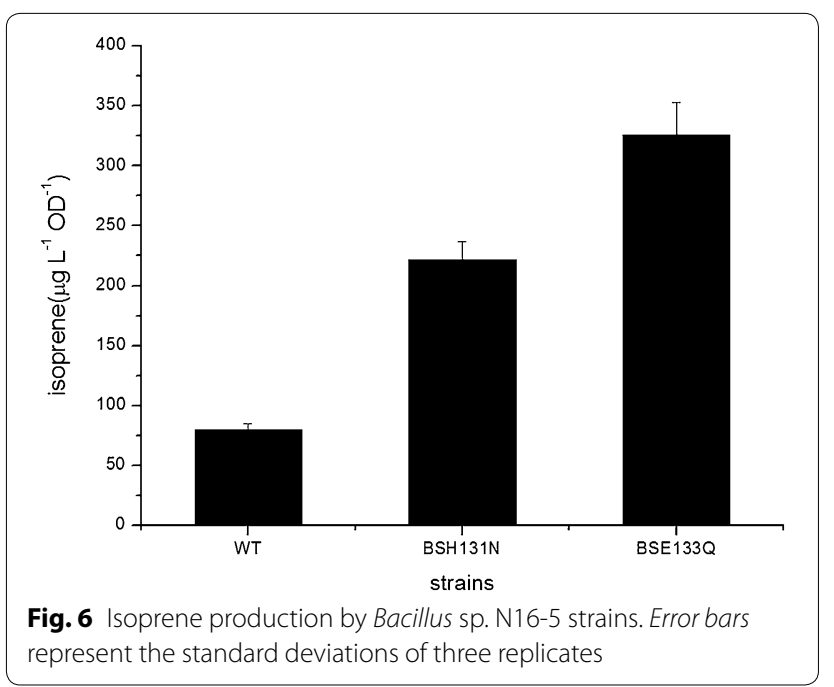


To some extent, isoprene can be seen as a byproduct generated by IspH in the process of transformation of HMBPP into IPP and DMAPP.

The basis of these two reactions is that the pyrophosphate group of HMBPP or DMAPP can be eliminated by IspH. In fact, for HMBPP, $\mathrm{PP}_{\mathrm{i}}$ is a better leaving group than an $\mathrm{OH}$ moiety, but conformational restrictions at the active site of $\mathrm{IspH}$ favour the $\mathrm{OH}$ group as the leaving group instead of pyrophosphate at the $\mathrm{C} 1$ position [23]. However, the formation of isoprene from HMBPP indicates that $\mathrm{PP}_{\mathrm{i}}$ can be still removed with low activity by $\mathrm{IspH}$. When the hydroxyl and pyrophosphate groups are all eliminated, the allyl intermediate forms, which would transform into isoprene instead of being protonated at the $\mathrm{C} 1$ and $\mathrm{C} 4$ positions; this proposed mechanism is supported by the data obtained in enzymatic activity assays in $\mathrm{D}_{2} \mathrm{O}$ buffer. In contrast, the formation of isoamylene from DMAPP would involve the introduction of a proton after the removal of $\mathrm{PP}_{\mathrm{i}}$. Whether the isoamylene formed was $2 \mathrm{M} 2 \mathrm{~B}$ or $3 \mathrm{M} 1 \mathrm{~B}$ depends on the position of protonation $(\mathrm{C} 1$ or $\mathrm{C} 3)$. Obviously, based on the product ratio of $2 \mathrm{M} 2 \mathrm{~B}$ to $3 \mathrm{M} 1 \mathrm{~B}$, the protonation preferentially occurs at the $\mathrm{C} 1$ position. Based on our results, the two unexpected reactions catalysed by IspH are reductive processes requiring an electron transfer system. Their potential catalytic mechanisms are shown in Fig. 7. Isoprene formation from HMBPP may include dehydroxylation leading to an allyl radical intermediate, followed by the elimination of pyrophosphate and the formation of isoprene (Fig. 7a). Isoamylene formation from DMAPP may include the elimination of pyrophosphate leading to an allyl anion intermediate, which is protonated either at $\mathrm{C} 1$ or $\mathrm{C} 3$ to form $2 \mathrm{M} 2 \mathrm{~B}$ or $3 \mathrm{M} 1 \mathrm{~B}$ (Fig. $7 \mathrm{~b}$ ). The strictly conserved amino acids His131 and Glu133 of IspH may play crucial roles in the protonation, a conclusion supported by the fact that the H131N and E133Q IspH mutants could catalyse the elimination of both the hydroxyl and pyrophosphate groups of HMBPP to form isoprene, but could not catalyse isoamylene formation which involves the protonation step. Further studies are required to explore the catalytic mechanisms of the unexpected promiscuous activities.

Isoprene synthase (IspS) is the enzyme responsible for isoprene biosynthesis in plants. This enzyme catalyses the formation of isoprene by elimination of pyrophosphate from DMAPP. A number of studies of IspS for isoprene production have been reported [32-34]. Here we demonstrated that IspH, especially the $\mathrm{H} 131 \mathrm{~N}$ and E133Q variants, could be used for isoprene production. IspH uses HMBPP as substrate to form isoprene, which has two advantages over IspS. First, the accumulation of prenyl diphosphate can be avoided in the host cell. In previous study [35], prenyl diphosphate toxicity was observed in E. coli expressing a heterologous MVA pathway. Similarly, cytotoxicity related to prenyl diphosphate accumulation was reported in B. subtilis [36]. Second, the number of enzymatic reactions for isoprene production can be reduced because HMBPP can be directly converted into isoprene.

To date, the enzyme responsible for isoprene synthesis in bacteria, especially the Bacillus species which can produce more isoprene than others, has not been identified. Many attempts have been made to isolate IspS from $B$. subtilis, but without success [7, 37]. In this study, IspH was serendipitously found to catalyse the formation of isoprene from HMBPP. It is probable that IspH is<smiles>C=CC(=C)C</smiles>

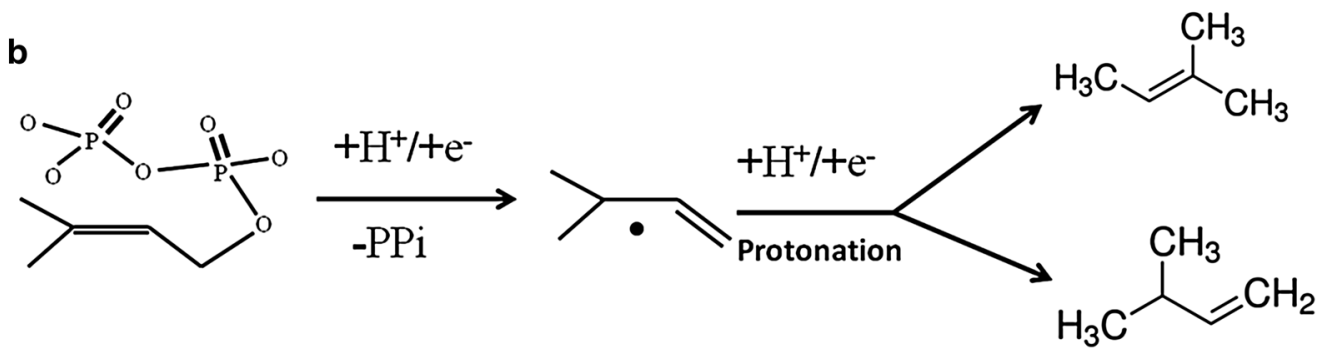

Fig. 7 Potential mechanisms of isoprene and isoamylene formation by IspH. a Isoprene from HMBPP; $\mathbf{b}$ Isoamylene from DMAPP 
responsible for isoprene production by bacteria. Isoprene may be a byproduct of IspH in the process of the transformation of HMBPP into IPP and DMAPP. Although, our results clearly demonstrate that IspH can catalyse isoprene formation from HMBPP, the existence of a specialized enzyme for isoprene synthesis in Bacillus sp. N16-5 cannot be ruled out. To investigate this question, we have attempted to disrupt the ispH gene in Bacillus sp. N16-5 in the presence of the MVA pathway from Enterococcus faecalis, but without success.

\section{Conclusions}

We have revealed two unexpected side reactions of IspH for the first time. These new discoveries provide important insight into the IspH protein, which is a putative target for antimicrobial drugs for the treatment of malaria and tuberculosis. IspH, especially the H131 N and E133Q IspH variants can catalyse isoprene formation from HMBPP, which may be a good alternative to IspS from plants for isoprene production. In addition, it is most probable that the promiscuous activity of IspH is the cause of isoprene production by bacteria. More details of the promiscuous activity of IspH will be investigated in future study.

\section{Methods}

\section{Bacterial strains and culture conditions}

The bacterial strains and plasmids used in this study are listed in Additional file 1: Table S2. E. coli strains were routinely grown in Luria-Bertani (LB) broth at $37^{\circ} \mathrm{C}$ on a rotary shaker at $220 \mathrm{rpm}$. For general purposes, Bacillus sp. N16-5 and its derivatives were grown aerobically in Horikoshi-I medium with $2 \% \mathrm{NaCl}$ (pH 10.0). To construct mutant strains, Bacillus sp. N16-5 and its derivatives were grown in complex neutral medium (NCM) ( $\mathrm{pH}$ 7.7) or SA5 agar medium [38]. When necessary, antibiotics were added to the growth media at the following concentrations: ampicillin, $100 \mu \mathrm{g} \mathrm{mL}^{-1}$; kanamycin, $50 \mu \mathrm{g} \mathrm{mL}^{-1}$; chloramphenicol, $12.5 \mu \mathrm{g} \mathrm{mL}^{-1}$. For selection of Bacillus sp. N16-5 transformants, the final antibiotic concentrations were chloramphenicol at $2.5 \mu \mathrm{g} \mathrm{mL}$ and erythromycin at $1 \mu \mathrm{g} \mathrm{mL}^{-1}$ in NCM or SA5 medium.

\section{Qualitative and quantitative analysis of isoamylene and isoprene}

For identification of isoamylene, a gas chromatographymass spectrometry (GC-MS) method was established as follows. An Agilent Technologies 7890B GC/5977A MSD that was equipped with an Agilent HP-PLOT $\mathrm{Al}_{2} \mathrm{O}_{3} / \mathrm{S} \mathrm{GC}$ Column $(25 \mathrm{~m}, 0.32 \mathrm{~mm}, 8.00 \mu \mathrm{m}, 7$-in. cage) with particle traps was used. Helium was used as the carrier gas at a flow rate of $2 \mathrm{~mL} \mathrm{~min}^{-1}$. The oven was kept at a constant temperature of $110^{\circ} \mathrm{C}$. To identify isoamylene production, peak retention times and mass spectra obtained from the bacterial headspace were compared with the retention time and mass spectrum of $2 \mathrm{M} 2 \mathrm{~B}$ and $3 \mathrm{M} 1 \mathrm{~B}$ standards (Sigma, St.Louis,MO, USA). For quantitative analysis of isoamylene production, bacterial strains were inoculated into headspace vials with Teflon-lined silicone septa at an inoculum concentration of $2 \%$ and grown for $12 \mathrm{~h}$ at $37^{\circ} \mathrm{C}$ on a rotary shaker at $220 \mathrm{rpm}$. The headspace of the medium was used as a negative control. A volume of $1 \mathrm{~mL}$ of headspace was sampled using a gastight syringe (SGE, Melbourne, Australia) and injected into the GC7800 GC inlet port (PuRui Instrument, Beijing, China), which had been equipped with a flame ionisation detector. The peak area was converted to isoamylene or isoprene concentration by comparing it with a standard curve that was plotted with a set of known concentrations of isoamylene or isoprene.

\section{Coexpression of ispH with fer in E. coli}

For coexpression of the Bacillus sp. N16-5 ispH and fer genes, the plasmid pSTV165HF was constructed as follows. The complete ispH gene was amplified by PCR, and the product was cloned into vector pSTV28 (TaKaRa, Shiga, Japan) between HindIII and BamHI sites, generating the plasmid pSTV165H. The fer gene was fused with the $\mathrm{P}_{\text {lac }}$ promoter and then ligated into $\mathrm{pSTV} 165 \mathrm{H}$ at the EcoRI and BamHI sites, to generate plasmid pSTV165HF. For coexpression of the $i s p H$ gene of $B$. subtilis 168 with the corresponding ferredoxin and the isp $H$ gene of $E$. coli K12 with the corresponding flavodoxin, plasmids pSTV168HF and pSTV12HF were constructed as described above. These three constructs were transformed into $E$. coli strain Trans109, and transformants were selected on LB agar supplemented with $25 \mu \mathrm{g} \mathrm{mL}{ }^{-1}$ chloramphenicol.

\section{Construction of mutant strains}

To construct Bacillus sp. N16-5 mutant strains and the plasmids pND1 and pND2, derivations of the shuttle vector pNNB194 [39] were used as gene deletion constructs. Each plasmid, which contained approximately $1.6 \mathrm{~kb}$ of DNA homologous to the deletion-flanking region, was constructed as follows. Two sets of primers (Additional file 1: Table S3) were designed; one set amplified an 800bp upstream fragment, which contained the $5^{\prime}$ region of each gene to be deleted, and the other amplified 800-bp of a downstream fragment, which contained the 3 ' region of the target gene. The two fragments were fused together by overlap extension PCR, and the product was digested with EcoRI and BamHI (NEB, Ipswich, USA) and ligated into the shuttle vector pNNB194, which had already been digested with the same enzymes. Finally, plasmids pND1 and pND2 were obtained. The deletion plasmids were transformed into Bacillus sp. N16-5 using the protoplast transformation procedure that was developed by Chenghua Gao [38], and 
transformants were selected on SA5 agar plates that had been supplemented with $1 \mu \mathrm{g} \mathrm{mL} \mathrm{L}^{-1}$ erythromycin at $34^{\circ} \mathrm{C}$. A single transformant was then inoculated into $\mathrm{NCM}$ medium, followed by double crossover and selection for the loss of the target gene from its locus. The final mutant clones were confirmed by PCR.

\section{Overexpression of ispH in Bacillus sp. N16-5}

Plasmid $\mathrm{pMH}$, which was used for ispH overexpression in Bacillus sp. N16-5 and its derivatives, was constructed as follows. The $i s p H$ gene was amplified by PCR with the primers listed in Additional file 1: Table S1 using N16-5 strain genomic DNA as the template. The PCR products were fused with the native Bacillus sp. N16-5 ldh promoter by overlap PCR, digested with EcoRI and BamHI (NEB), and ligated into the corresponding site of the shuttle vector pMK4 [40] to create $\mathrm{pMH}$. This plasmid with the $i s p H$ gene under transcriptional control of the $\mathrm{P}_{\text {ldh }}$ promoter was then transformed into Bacillus sp. N16-5 and the corresponding mutant strains using a protoplast transformation method [38].

\section{Expression and purification of recombinant proteins}

For expression of IspH, ferredoxin and ferredoxin$\mathrm{NADP}^{+}$-reductase from Bacillus sp. N16-5, their open reading frames were amplified by PCR, and the amplified fragments were cloned into the $\mathrm{NcoI} / \mathrm{Xhol}$ sites of pET-28a (+) (TaKaRa, Shiga, Japan) to yield pET-ispH, pET-fer and pET-fnr, respectively, followed by transformation into E. coli BL21 (DE3) cells. To improve IspH protein-specific activity, a ispH hyperexpression strain was constructed using the method of Gräwert et al. [15]. Part of the isc operon from E. coli was amplified by PCR using high-fidelity DNA polymerase. The products were digested with KpnI and PstI and then ligated into the corresponding site of vector pSTV28 (TaKaRa, Shiga, Japan). The resulting plasmid pST-isc was transformed into E. coli BL21 (DE3) harbouring the pET-ispH plasmid. The recombinant strain was grown in LB medium supplemented with kanamycin $\left(50 \mu \mathrm{g} \mathrm{mL} \mathrm{m}^{-1}\right)$ and chloramphenicol $\left(25 \mu \mathrm{g} \mathrm{mL}^{-1}\right)$ at $37^{\circ} \mathrm{C}$. When the $\mathrm{OD}_{600}$ reached approximately 0.6 , cysteine $(1 \mathrm{mM}), \mathrm{FeCl}_{3}(0.1 \mathrm{mM})$ and IPTG $(0.1 \mathrm{mM})$ were added to the culture, which was then incubated for $16 \mathrm{~h}$ at $18{ }^{\circ} \mathrm{C}$ on a rotary shaker at $110 \mathrm{rpm}$. The cells were harvested by centrifugation, washed twice with $\mathrm{ddH}_{2} \mathrm{O}$, and stored at $-80^{\circ} \mathrm{C}$.

Purification of recombinant proteins was performed in anaerobic conditions in a glovebox (Shel Lab, Cornelius, Oregon, USA) that had been flushed with a gas mixture of $95 \% \mathrm{~N}_{2}$ and $5 \% \mathrm{H}_{2}$. Residual $\mathrm{O}_{2}$ was removed with palladium catalysts. Buffers were equilibrated overnight in the tent under stirring and were degassed by ultrasound before use. The harvested cells were resuspended and lysed in BugBuster Protein Extraction Reagent (Merck, Darmstadt, Germany) by pipetting or gentle vortexing for $20 \mathrm{~min}$ at room temperature and then centrifuged at $16,000 \times g$ for $20 \mathrm{~min}$ at $4{ }^{\circ} \mathrm{C}$. The supernatant was applied to a Ni-NTA column that had been equilibrated with $20 \mathrm{mM}$ Tris- $\mathrm{HCl}, \mathrm{pH} 7.8$, containing $5 \mathrm{mM}$ imidazole and $150 \mathrm{mM} \mathrm{NaCl}$. After washing with $20 \mathrm{mM}$ imidazole, protein was eluted with $250 \mathrm{mM}$ imidazole. Fractions were collected and desalted with a desalting column (Sangon Biotech, Shanghai, China). The purified protein was flashfrozen in liquid nitrogen and stored at $-80^{\circ} \mathrm{C}$ until use.

\section{Enzymatic activity assays}

Enzyme-catalysed reactions were performed in $5-\mathrm{mL}$ sealed chromatography vials in anaerobic conditions in a glovebox. Assay mixtures contained $150 \mathrm{mM} \mathrm{NaCl}$, $20 \mathrm{mM}$ Tris- $\mathrm{HCl}$ (pH 7.8), $2 \mathrm{mM}$ DTT, $1 \mathrm{mM}$ NADPH, $1 \mathrm{mM}$ DMAPP (unless otherwise stated), $20 \mu \mathrm{M}$ Fd, $5 \mu \mathrm{M}$ FNR and $0.5 \mu \mathrm{M}$ IspH. The total volume was $500 \mu \mathrm{L}$. To test the IspH protein substrate, DMAPP in the mixtures was replaced with IPP or HMBPP. After the mixtures were ready, the vial was immediately sealed and incubated at $37{ }^{\circ} \mathrm{C}$ for $1 \mathrm{~h}$. Headspace gas $(1 \mathrm{~mL})$ was sampled with a needle and syringe. Headspace of the mixtures with no substrate was run as a negative control. To avoid creating a vacuum in the vial, $1 \mathrm{~mL}$ water was injected into the vial concurrent with the removal of the headspace.

\section{Site-directed mutagenesis}

To investigate the roles of specific protein residues in catalytic activity, site-directed mutagenesis was performed using mismatch PCR as follows. The entire pSTV165HF plasmid was amplified by PCR using high-fidelity DNA polymerase with mutagenic primers. The amplification products were digested with $D p n \mathrm{I}$ for $2 \mathrm{~h}$ at $37^{\circ} \mathrm{C}$ and then transformed into competent E. coli strain DMT (TransGene Biotech, Beijing, China). Transformants were selected on LB-agar plates supplemented with $25 \mu \mathrm{g} \mathrm{mL}{ }^{-1}$ erythromycin, and the final mutant clones were confirmed by sequencing. The mutant plasmids were extracted and transformed into E. coli Trans 109.

\section{Additional file}

Additional file 1. This file consists of five supplemental figures and three supplemental tables. Figure $\mathbf{S 1}$ and Figure $\mathbf{S 2}$ present additional information on identification of 3-methyl-1-butene, 2-methyl-2-butene and isoprene. Table $\mathbf{S 1}$ presents isoamylene and isoprene production in various conditions. Figure $\mathbf{S} \mathbf{3}$ presents Michaelis-Menten plots of the activity of recombinant IspH toward DMAPP. Figure $\mathbf{S 4}$ shows isoamylene production by recombinant strains expressing IspH variants. Figure S5 presents GC profile of 3-methyl-1-butene and 2-methyl-2-butene produced. Table $\mathbf{S} \mathbf{2}$ and Table $\mathbf{S} \mathbf{3}$ list strains, plasmids and primers used in this study. 


\begin{abstract}
Abbreviations
MEP: methylerythritol phosphate; MVA: mevalonic acid; HMBPP: (E)-4-hydroxy3-methyl-2-butenyl diphosphate; IPP: isopentenyl diphosphate; DMAPP: dimethylallyl diphosphate; IspH: (E)-4-hydroxy-3-methyl-2-butenyl diphosphate reductase; IspS: isoprene synthase; 2M2B: 2-methyl-2-butene; 3M1B: 3-methyl-1-butene; FNR: ferredoxin-NADP ${ }^{+}$reductase; Fd: ferredoxin; $\mathrm{OD}_{600}$ : the optical density at $600 \mathrm{~nm}$.
\end{abstract}

\section{Authors' contributions}

$D G, Y X$ and $Y M$ designed the project; DG performed experiments; DG and $Y X$ analysed the data; DG and $Y X$ wrote the manuscript. All authors read and approved the final manuscript.

\section{Author details}

1 State Key Laboratory of Microbial Resources, Institute of Microbiology, Chinese Academy of Sciences, Beijing 100101, People's Republic of China. ${ }^{2}$ University of Chinese Academy of Sciences, Beijing 100049, People's Republic of China. ${ }^{3}$ College of Medicine, Anhui University of Science and Technology, Huainan, People's Republic of China.

\section{Acknowledgements}

This work was supported by Grants from the Ministry of Sciences and Technology of China (Grant Nos. 2011CBA00800, 2013CBA733900, 2012AA022100, and 2011AA02A200).

\section{Competing interests}

The authors declare that they have no competing interests.

Received: 8 February 2016 Accepted: 27 April 2016

Published online: 11 May 2016

\section{References}

1. Gelmont D, Stein RA, Mead JF. Isoprene-the main hydrocarbon in human breath. Biochem Biophys Res Commun. 1981;99:1456-60.

2. Monson RK, Fall R. Isoprene emission from aspen leaves: influence of environment and relation to photosynthesis and photorespiration. Plant Physiol. 1989;90:267-74

3. Kuzma J, Nemecek-Marshall M, Pollock WH, Fall R. Bacteria produce the volatile hydrocarbon isoprene. Curr Microbiol. 1995;30:97-103.

4. Miller B, Oschinski C, Zimmer W. First isolation of an isoprene synthase gene from poplar and successful expression of the gene in Escherichia coli. Planta. 2001;213:483-7.

5. Sharkey TD, Yeh S, Wiberley AE, Falbel TG, Gong D, Fernandez DE. Evolution of the isoprene biosynthetic pathway in kudzu. Plant Physiol. 2005;137:700-12.

6. Koksal M, Zimmer I, Schnitzler JP, Christianson DW. Structure of isoprene synthase illuminates the chemical mechanism of teragram atmospheric carbon emission. J Mol Biol. 2010;402:363-73.

7. Sivy TL, Shirk MC, Fall R. Isoprene synthase activity parallels fluctuations of isoprene release during growth of Bacillus subtilis. Biochem Biophys Res Commun. 2002;294:71-5

8. Rohmer M, Knani M, Simonin P, Sutter B, Sahm H. Isoprenoid biosynthesis in bacteria: a novel pathway for the early steps leading to isopentenyl diphosphate. Biochem J. 1993;295(Pt 2):517-24.

9. Paseshnichenko VA. A new alternative non-mevalonate pathway for isoprenoid biosynthesis in eubacteria and plants. Biochemistry (Mosc). 1998:63:139-48.

10. Rohmer M. The discovery of a mevalonate-independent pathway for isoprenoid biosynthesis in bacteria, algae and higher plants. Nat Prod Rep. 1999;16:565-74.

11. Zhao L, Chang WC, Xiao Y, Liu HW, Liu P. Methylerythritol phosphate pathway of isoprenoid biosynthesis. Annu Rev Biochem. 2013;82:497-530.

12. Rohdich F, Hecht S, Gartner K, Adam P, Krieger C, Amslinger S, Arigoni D, Bacher A, Eisenreich W. Studies on the nonmevalonate terpene biosynthetic pathway: metabolic role of IspH (LytB) protein. Proc Natl Acad Sci. 2002:99:1158-63.
13. Rohdich F, Zepeck F, Adam P, Hecht S, Kaiser J, Laupitz R, Grawert T, Amslinger S, Eisenreich W, Bacher A, Arigoni D. The deoxyxylulose phosphate pathway of isoprenoid biosynthesis: studies on the mechanisms of the reactions catalyzed by IspG and IspH protein. Proc Natl Acad Sci. 2003;100:1586-91.

14. Wolff M, Seemann M, Tse Sum Bui B, Frapart Y, Tritsch D, Garcia Estrabot A, Rodriguez-Concepcion M, Boronat A, Marquet A, Rohmer M. Isoprenoid biosynthesis via the methylerythritol phosphate pathway: the (E)4-hydroxy-3-methylbut-2-enyl diphosphate reductase $(\mathrm{LytB} / \mathrm{IspH})$ from Escherichia coli is a [4Fe - 4S] protein. FEBS Lett. 2003;541:115-20.

15. Grawert T, Kaiser J, Zepeck F, Laupitz R, Hecht S, Amslinger S, Schramek N, Schleicher E, Weber S, Haslbeck M, et al. IspH protein of Escherichia coli: studies on iron-sulfur cluster implementation and catalysis. J Am Chem Soc. 2004; 126:12847-55.

16. Seemann M, Janthawornpong K, Schweizer J, Bottger LH, Janoschka A, Ahrens-Botzong A, Tambou EN, Rotthaus O, Trautwein AX, Rohmer $M$. Isoprenoid biosynthesis via the MEP pathway: in vivo Mossbauer spectroscopy identifies a [4Fe $-4 \mathrm{~S}]^{2+}$ center with unusual coordination sphere in the LytB protein. J Am Chem Soc. 2009;131:13184-5.

17. Puan KJ, Wang H, Dairi T, Kuzuyama T, Morita CT. fldA is an essential gene required in the 2-C-methyl-D-erythritol 4-phosphate pathway for isoprenoid biosynthesis. FEBS Lett. 2005;579:3802-6.

18. Rohrich RC, Englert N, Troschke K, Reichenberg A, Hintz M, Seeber F, Balconi E, Aliverti A, Zanetti G, Kohler U, et al. Reconstitution of an apicoplast-localised electron transfer pathway involved in the isoprenoid biosynthesis of Plasmodium falciparum. FEBS Lett. 2005;579:6433-8.

19. Xiao Y, Chang WC, Liu HW, Liu P. Study of IspH, a key enzyme in the methylerythritol phosphate pathway using fluoro-substituted substrate analogues. Org Lett. 2011;13:5912-5.

20. Wang W, Wang K, Span I, Jauch J, Bacher A, Groll M, Oldfield E. Are free radicals involved in IspH catalysis? An EPR and crystallographic investigation. J Am Chem Soc. 2012;134:11225-34.

21. Span I, Wang K, Wang W, Zhang Y, Bacher A, Eisenreich W, Li K, Schulz C, Oldfield E, Groll M. Discovery of acetylene hydratase activity of the ironsulphur protein IspH. Nat Commun. 2012;3:1042.

22. Rekittke I, Wiesner J, Rohrich R, Demmer U, Warkentin E, Xu W, Troschke K, Hintz M, No JH, Duin EC, et al. Structure of (E)-4-hydroxy-3-methyl-but2-enyl diphosphate reductase, the terminal enzyme of the non-mevalonate pathway. J Am Chem Soc. 2008;130:17206-7.

23. Grawert T, Rohdich F, Span I, Bacher A, Eisenreich W, Eppinger J, Groll M. Structure of active IspH enzyme from Escherichia coli provides mechanistic insights into substrate reduction. Angew Chem Int Ed Engl. 2009;48:5756-9.

24. Wang W, Wang K, Liu YL, No JH, Li J, Nilges MJ, Oldfield E. Bioorganometallic mechanism of action, and inhibition, of IspH. Proc Natl Acad Sci. 2010;107:4522-7.

25. Span I, Grawert T, Bacher A, Eisenreich W, Groll M. Crystal structures of mutant IspH proteins reveal a rotation of the substrate's hydroxymethyl group during catalysis. J Mol Biol. 2012;416:1-9.

26. Grawert T, Span I, Eisenreich W, Rohdich F, Eppinger J, Bacher A, Groll $M$. Probing the reaction mechanism of IspH protein by $x$-ray structure analysis. Proc Natl Acad Sci. 2010;107:1077-81.

27. Fisher AJ, Rosenstiel TN, Shirk MC, Fall R. Nonradioactive assay for cellular dimethylallyl diphosphate. Anal Biochem. 2001;292:272-9.

28. Weise SE, Li Z, Sutter AE, Corrion A, Banerjee A, Sharkey TD. Measuring dimethylallyl diphosphate available for isoprene synthesis. Anal Biochem. 2013:435:27-34.

29. Jomaa H, Wiesner J, Sanderbrand S, Altincicek B, Weidemeyer C, Hintz M, Turbachova I, Eberl M, Zeidler J, Lichtenthaler HK, et al. Inhibitors of the nonmevalonate pathway of isoprenoid biosynthesis as antimalarial drugs. Science. 1999;285:1573-6.

30. Wiesner J, Jomaa H. Isoprenoid biosynthesis of the apicoplast as drug target. Curr Drug Targets. 2007;8:3-13.

31. Heuston S, Begley M, Gahan CG, Hill C. Isoprenoid biosynthesis in bacterial pathogens. Microbiology. 2012;158:1389-401.

32. Lindberg P, Park S, Melis A. Engineering a platform for photosynthetic isoprene production in cyanobacteria, using Synechocystis as the model organism. Metab Eng. 2010;12:70-9. 
33. Hong SY, Zurbriggen AS, Melis A. Isoprene hydrocarbons production upon heterologous transformation of Saccharomyces cerevisiae. J App Microbiol. 2012;113:52-65.

34. Yang J, Zhao G, Sun Y, Zheng Y, Jiang X, Liu W, Xian M. Bio-isoprene production using exogenous MVA pathway and isoprene synthase in Escherichia coli. Bioresour Technol. 2012;104:642-7.

35. Martin VJ, Pitera DJ, Withers ST, Newman JD, Keasling JD. Engineering a mevalonate pathway in Escherichia coli for production of terpenoids. Nat Biotechnol. 2003;21:796-802.

36. Sivy $T L$, Fall R, Rosenstiel TN. Evidence of isoprenoid precursor toxicity in Bacillus subtilis. Biosci Biotechnol Biochem. 2011:75:2376-83.

37. Withers ST, Gottlieb SS, Lieu B, Newman JD, Keasling JD. Identification of isopentenol biosynthetic genes from Bacillus subtilis by a screening method based on isoprenoid precursor toxicity. Appl Environ Microbiol. 2007;73:6277-83
38. Gao C, Xue Y, Ma Y. Protoplast transformation of recalcitrant alkaliphilic Bacillus sp. with methylated plasmid DNA and a developed hard agar regeneration medium. PLOS ONE. 2011;6:e28148.

39. Connelly MB, Young GM, Sloma A. Extracellular proteolytic activity plays a central role in swarming motility in Bacillus subtilis. J Bacteriol. 2004;186:4159-67.

40. Sullivan MA, Yasbin RE, Young FE. New shuttle vectors for Bacillus subtilis and Escherichia coli which allow rapid detection of inserted fragments. Gene. 1984;29:21-6.

\section{Submit your next manuscript to BioMed Central and we will help you at every step:}

- We accept pre-submission inquiries

- Our selector tool helps you to find the most relevant journal

- We provide round the clock customer support

- Convenient online submission

- Thorough peer review

- Inclusion in PubMed and all major indexing services

- Maximum visibility for your research

Submit your manuscript at www.biomedcentral.com/submit 